Adam G. Hart • Francis L.W. Ratnieks

\title{
Why do honey-bee (Apis mellifera) foragers transfer nectar to several receivers? Information improvement through multiple sampling in a biological system
}

Published online: 21 February 2001

(C) Springer-Verlag 2001

Behav Ecol Sociobiol (2000)

DOI 10.1007/s002650000306

There was a spelling error in the title of this paper: "millifera" should read "mellifera". The correct title is given above.

The online version of the original article can be found at http://dx.doi.org/10.1007/s002650000306

A.G. Hart (ه) · F.L.W. Ratnieks

Department of Animal and Plant Sciences, University of Sheffield, Sheffield, S10 2TN, UK

e-mail: bop98agh@sheffield.ac.uk

Tel.: +44-114-2220149, Fax: +44-114-2760159 